\title{
Maximum sinking velocities of suspended particulate matter in a coastal transition zone
}

\author{
Joeran Maerz ${ }^{1, a}$, Richard Hofmeister ${ }^{1}$, Eefke M. van der Lee ${ }^{1}$, Ulf Gräwe ${ }^{2,3}$, Rolf Riethmüller ${ }^{1}$, and Kai W. Wirtz ${ }^{1}$ \\ ${ }^{1}$ Institute of Coastal Research, Helmholtz-Zentrum Geesthacht (HZG), Geesthacht, Germany \\ ${ }^{2}$ Leibniz Institute for Baltic Sea Research, Warnemünde, Germany \\ ${ }^{3}$ Institute of Meteorology and Climatology, Leibniz University Hanover, Hanover, Germany \\ a present address: Max Planck Institute for Meteorology (MPI-M), Hamburg, Germany
}

Correspondence to: Joeran Maerz (joeran.maerz@mpimet.mpg.de)

Received: 29 December 2015 - Published in Biogeosciences Discuss.: 5 February 2016

Revised: 22 July 2016 - Accepted: 27 July 2016 - Published: 5 September 2016

\begin{abstract}
Marine coastal ecosystem functioning is crucially linked to the transport and fate of suspended particulate matter (SPM). Transport of SPM is controlled by, amongst other factors, sinking velocity $w_{\mathrm{s}}$. Since the $w_{\mathrm{s}}$ of cohesive SPM aggregates varies significantly with size and composition of the mineral and organic origin, $w_{\mathrm{s}}$ exhibits large spatial variability along gradients of turbulence, SPM concentration (SPMC) and SPM composition. In this study, we retrieved $w_{\mathrm{s}}$ for the German Bight, North Sea, by combining measured vertical turbidity profiles with simulation results for turbulent eddy diffusivity. We analyzed $w_{\mathrm{s}}$ with respect to modeled prevailing dissipation rates $\epsilon$ and found that mean $w_{\mathrm{s}}$ were significantly enhanced around $\log _{10}\left(\epsilon\left(\mathrm{m}^{2} \mathrm{~s}^{-3}\right)\right) \approx$ -5.5 . This $\epsilon$ region is typically found at water depths of approximately 15 to $20 \mathrm{~m}$ along cross-shore transects. Across this zone, SPMC declines towards the offshore waters and a change in particle composition occurs. This characterizes a transition zone with potentially enhanced vertical fluxes. Our findings contribute to the conceptual understanding of nutrient cycling in the coastal region which is as follows. Previous studies identified an estuarine circulation. Its residual landward-oriented bottom currents are loaded with SPM, particularly within the transition zone. This retains and traps fine sediments and particulate-bound nutrients in coastal waters where organic components of SPM become remineralized. Residual surface currents transport dissolved nutrients offshore, where they are again consumed by phytoplankton. Algae excrete extracellular polymeric substances which are known to mediate mineral aggregation and thus sedimentation. This probably takes place particularly in the transition
\end{abstract}

zone and completes the coastal nutrient cycle. The efficiency of the transition zone for retention is thus suggested as an important mechanism that underlies the often observed nutrient gradients towards the coast.

\section{Introduction}

Biogeochemical cycling and functioning of marine coastal and shelf sea systems crucially relies on particle transport. Vertical fluxes of suspended particulate matter (SPM) are determined by sinking velocity $w_{\mathrm{s}}$ and indirectly affect the horizontal transport. In coastal systems, SPM is composed of living and nonliving particulate organic matter (POM) and fine cohesive and non-cohesive resuspended minerals. Fine-grained minerals of sizes typically up to $8 \mu \mathrm{m}$ (Chang et al., 2006) and POM can undergo aggregation and fragmentation processes that change sinking velocity and thus transport properties. As a consequence of flocculation, SPM aggregates ubiquitously possess a broad spectrum of size and composition (Fettweis, 2008). This heterogeneity between flocs increases the methodological effort required to analyze $w_{\mathrm{s}}$ in situ (Fettweis, 2008). On larger scales, SPM concentration (SPMC) and composition additionally exhibit strong spatiotemporal variability that is the result of manifold interplaying processes. Tidal and wind-induced currents are the major driver for resuspension and subsequent horizontal transport, while biological processes, such as algae growth and bio-induced sediment stabilization (Black et al., 2002; Stal, 2003), interfere and thus shape the complex 
distribution of SPM in coastal and estuarine systems. Typically, SPMC and composition show cross-shore gradients (Tian et al., 2009; van der Lee et al., 2009; Li et al., 2010).

In shallow waters near the coast, where turbulence and thus resuspension are high, SPMC consists of flocs that are mainly composed of mineral particles with high densities. By contrast, in deeper offshore regions, SPMC is lower and the flocs are looser and more organic. This general pattern of changing SPMC and composition from coast to open waters is typical for our research area, the German Bight (Eisma and Kalf, 1987), and is observed worldwide in estuaries (e.g., Fugate and Friedrichs, 2003) and across coastal seas (e.g., van der Lee et al., 2009). Since both SPMC and turbulence control the $w_{\mathrm{s}}$ of cohesive material (Pejrup and Mikkelsen, 2010), it is likely that these cross-shore SPM gradients induce considerable spatial variability in $w_{\mathrm{s}}$ and thus affect the transport and fate of SPM in coastal marine systems. However, to date and to the authors' knowledge, no comprehensive analysis has addressed system-wide cross-shore gradients in sinking velocity, especially in relation to possible drivers.

The sinking velocity of SPM is determined by floc size and density, both resulting from a complex interplay of processes. Particle size distribution is locally governed by restructuring (Becker et al., 2009), aggregation and processes mainly driven by turbulence-induced shear, $\bar{G}=(\epsilon / \nu)^{1 / 2}$ (Pejrup and Mikkelsen, 2010). This turbulence is generated by energy dissipation $\epsilon$ (Camp and Stein, 1943) with kinematic viscosity $v$. Under a given shear regime, aggregation is controlled by floc volume concentration and the adhesion properties of the primary particles of mineral and organic origin that form the floc. The higher the volume concentration of flocs, the higher is the encounter rate. Subsequently, adhesion forces of the particles involved eventually determine the probability of the particles sticking together. In addition, adhesive forces limit the intrusion of particles during clustering and loosen the floc structure (Meakin and Jullien, 1988). This leads to a floc morphology that shows self-similar fractal scaling (Kranenburg, 1994). As a result, aggregates possess decreased density compared to the aggregates comprising primary particles. In addition, adhesion forces between the particles within a floc strengthen the resistance of aggregates to fragmentation (Kranenburg, 1999), while the smallest eddies, with sizes on the Kolmogorov microscale (Kolmogorov, 1941), potentially limit the maximum particle size (Berhane et al., 1997). In sum, $w_{\mathrm{s}}$ is locally governed by turbulencedriven processes whose rates depend on the physicochemical properties and volume concentration of particles.

To date, there is still a lack of understanding of how environmental conditions and especially biological processes affect physicochemical properties and thus $w_{\mathrm{s}}$ of cohesive SPM. Typically, a power law relation between median $w_{\mathrm{s}}$ and SPMC is postulated and found at local measurements (Dyer, 1989). However, these relations vary considerably in their power factor among different systems as summa- rized by Dyer (1989) for various estuaries. This variation can be attributed to different shear stresses and physicochemical properties of the particles involved. They are particularly subjected to algae and microbial extracellular polymeric substance (EPS) excretions such as transparent exopolymer particles (TEPs) that are known to mediate aggregation processes. TEPs bridge and glue mineral particles together (Decho, 1990) and potentially increase resistance to particle fragmentation (Fettweis et al., 2014). By these mechanisms, TEPs are hypothesized to enable phytoplankton to clear the water column of suspended sediments (Fettweis et al., 2014). Such clearing ability may contribute to spatial variability of $w_{\mathrm{s}}$, which would affect biogeochemical cycles. So far, knowledge on spatial variations of $w_{\mathrm{s}}$ on a system scale is rare. A study on a transect in San Francisco Bay has been carried out (Manning and Schoellhamer, 2013), but generally, there is no systematic understanding of the relevance of sedimentation variability for biogeochemical cycles in coastal ecosystems. Such knowledge, though, is needed to understand and model coastal shelf biogeochemistry and sedimentology. For example, it is still an ongoing scientific discussion which processes are involved and to what extent they sustain the net sediment transport towards the Dutch, German and Danish coast into the Wadden Sea (Postma, 1984). We therefore aim at a reconstruction and analysis of the $w_{\mathrm{s}}$ of SPM for the German Bight, North Sea. We develop a new approach to retrieve $w_{\mathrm{s}}$ from high-resolution turbidity profiles in combination with vertical mixing rates estimated by a hydrodynamical model. Our findings are discussed particularly in light of their relevance for biogeochemical cycling of matter in coastal waters.

\section{Methods}

In the following section, the study area, sampling and preprocessing of observational data are described. We further explain the procedure for extracting sinking velocities from observations with the aid of hydrodynamical model results.

\subsection{Study area}

The surveyed area of the German Bight (Fig. 1) is located in the southeast of the North Sea and features a typical depth of about $30 \mathrm{~m}$ to a maximum of $50 \mathrm{~m}$. The North Sea is a shallow shelf sea with an average depth of $80 \mathrm{~m}$ (Sündermann and Pohlmann, 2011) and is connected to the North Atlantic via the English Channel in the southwest and opens towards the north, spanning the European continental shelf. The North Sea is exposed to tides whose tidal range is between approximately 1.8 and $3.4 \mathrm{~m}$ in the southeastern German Bight. The main North Sea tidal wave turns counterclockwise and drives the large-scale current system (Sündermann and Pohlmann, 2011). SPM originating from the British coast is transported eastwards by the East Anglian 


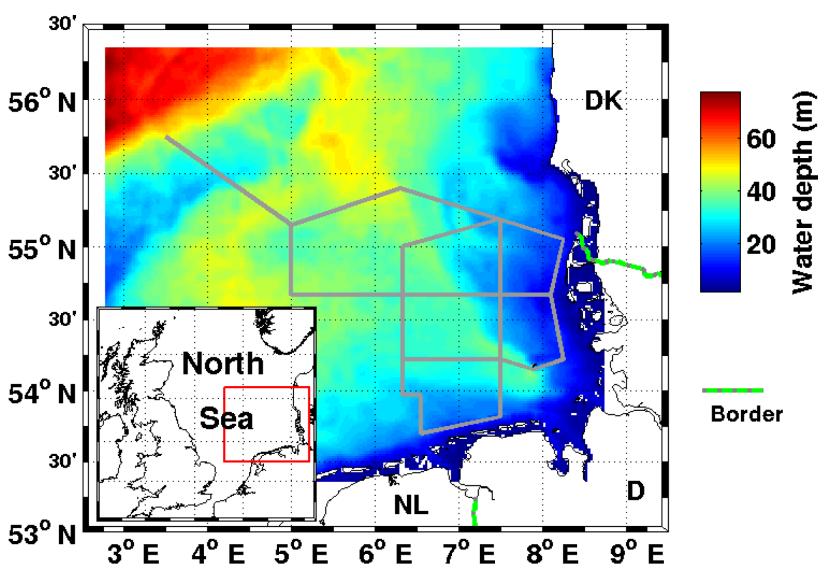

Figure 1. Map of water depth in the German Bight. Gray lines indicate the ScanFish sampling transects. The inset shows the North Sea and in red the region in the larger drawing. For East and North Frisian subregions, see Fig. 7.

Plume and occasionally reaches the surveyed area (Fettweis et al., 2012; Pietrzak et al., 2011). In the southern North Sea, SPM and dissolved nutrients that enter through the River Rhine are transported eastward along the Dutch and German East Frisian shore by this large-scale current system. In addition, the German rivers Ems, Weser and Elbe discharge into the German Bight. As a result of the riverine nutrient input, the German Bight features a generally high primary productivity (Joint and Pomroy, 1993) while it possesses pronounced heterogeneity with strong cross-shore gradients in (i) nutrients (Brockmann et al., 1990; Ebenhöh et al., 2004) and (ii) SPMC and composition (Eisma and Kalf, 1987). The near-coastal waters of the German Bight are characterized by relatively high SPMC of few to several hundred grams per cubic meter in near-bottom regions. SPMC possesses a pronounced seasonality, showing higher values in winter than in summer. In the shallow parts of the tidal back barriers of the Wadden Sea, this seasonal pattern is reflected by the bottom fraction of fine, cohesive sediments accumulating during spring and summer due to aggregation and subsequent increased sedimentation (Chang et al., 2006). The sediment catchment area for the Dutch and East Frisian Wadden Sea system, an area sheltered from the North Sea by a chain of islands, is hypothesized to be defined by a line of no return located alongshore off the coast (Postma, 1984). The line of no return is conceptually described as an imaginary line beyond which particles escape coastal trapping mechanisms such as density gradient-driven undercurrents (Postma, 1984).

\subsection{Sampling and processing of observational data}

Measurements were carried out as part of the "Coastal Observing System for Northern and Arctic Seas" project (COSYNA: www.cosyna.de; see also Baschek et al., 2016). Sensors were mounted on board a towed vehicle (Scan-
Fish, Mark II, EIVA a/s, Denmark). The ScanFish was remotely operated behind a vessel sailing with a speed of 6 to 8 knots. Cruises were carried out during May, JulyAugust and September 2009; March, May, July and September 2010; and April, June and September 2011 during moderate weather conditions. No winter measurements were carried out. The transect grid covered the German Exclusive Economic Zone (Fig. 1). The ScanFish was forced to operate in nearly V-curved undulating path mode between approximately $3 \mathrm{~m}$ below the water surface and the sea bottom, with a vertical speed of $0.4 \mathrm{~m} \mathrm{~s}^{-1}$ and a sampling rate of $11 \mathrm{~Hz}$, yielding a vertical data spacing of about $0.04 \mathrm{~m}$. Our analysis considered measurements of specific conductance (Conductivity Sensor, ADM Elektronik, Germany), water temperature $T$ (PT100, ADM Elektronik, Germany), pressure $p$ (PA-7, Keller AG, Switzerland), optical turbidity (Seapoint Turbidity Meter $880 \mathrm{~nm}$, Seapoint Sensors inc., USA) and chlorophyll $a$ fluorescence F (TriOS MicroFlu-chl, TRIOS Inc., Germany). Specific conductivity and $T$ were calibrated against reference standards directly before and after the ship surveys. Potential water density $\rho_{\theta}$, expressed as $\sigma_{\mathrm{T}}=\rho_{\theta}-1000 \mathrm{~kg} \mathrm{~m}^{-3}$, was calculated according to the EOS-80 equations of state (Fofonoff and Millard, 1983). Thermal lag effects were visible in $\sigma_{\mathrm{T}}$ near the thermoclines, but this effect was neglected since the selection criteria for profiles diminished their relevance for this analysis, as described below. During post-processing, data generally underwent tests for any stuck values and spikes and were finally visually inspected to remove remaining faults. Turbidity, measured in formazine turbidity units (FTU), was converted to SPMC using a factor of $1.08 \mathrm{~g}$ (dry weight) $\mathrm{m}^{-3} \mathrm{FTU}^{-1}$ that was determined by linear regression $\left(r^{2}=0.967\right.$; Röttgers et al., 2011). Laboratory investigations revealed a sensitivity of the fluorescence signal to turbidity. Therefore, a correction factor was applied to measured fluorescence. A factor of $(0.32+(1-0.32) \exp (-0.025 \text { turbidity }))^{-1}$ was experimentally determined with commercially available chlorophyll $a$ dissolved in varying formazine concentrations. As a final step, data sets were split into up- and down casts between consecutive vertical extrema of the undulating flight path. Casts with deficient pressure data were discarded.

\subsection{Data processing and sinking velocity extraction}

Sinking velocities were obtained by fitting an analytical solution of the vertical distribution of SPMC to observations. Assuming steady state and neglecting horizontal advection, the SPM transport equation in time $t$ for concentration $C$ reduces to

$\frac{\partial}{\partial t} C=\frac{\partial}{\partial z} k_{\mathrm{v}} \frac{\partial}{\partial z} C-\frac{\partial}{\partial z}\left(w_{\mathrm{s}} C\right)=0$.

This describes the balance between fluxes in the positively downward pointing vertical direction $z$ due to sinking and turbulent eddy diffusivity $k_{\mathrm{v}}$. If we assume that the sinking timescale is larger than the tidal period, we can simplify 
Eq. (1) by using the vertically averaged $k_{\mathrm{v}}$ of a profile. This assumes a rather homogeneous turbulence intensity which we account for in the data processing described below. If we further allow fluxes across profiles borders, which cancel out under steady state, we can derive an analytical model $\left(C_{\mathrm{m}}(z)\right)$ for depth-dependent SPMC:

$C_{\mathrm{m}}(z)=\frac{\lambda \exp \left(\lambda z^{*} / H_{\mathrm{p}}\right)}{\exp (\lambda)-1}\langle C\rangle \quad$ where $\lambda=\frac{w_{\mathrm{s}} H_{\mathrm{p}}}{\left\langle k_{\mathrm{v}}\right\rangle}$.

Here, $H_{\mathrm{p}}$ represents the profile height and $z^{*}=z-z_{1}$, where $z_{1}$ is the depth at which the profile starts. The application of the analytical solution to observed SPMC profiles requires information on corresponding $k_{\mathrm{v}}$ values. These and energy dissipation rate $\epsilon$ and water density $\sigma_{\mathrm{T}}$ were obtained from hydrodynamical simulations of Gräwe et al. (2015), based on a $1 \mathrm{nmi}$ numerical model of the North Sea and the Baltic Sea. In the vertical, 42 terrain-following levels were used. Vertical mixing was parametrized by means of a two-equation $k-\epsilon$ turbulence model coupled to an algebraic second-moment closure (Canuto et al., 2001). The implementation of the turbulence module was done via the General Ocean Turbulence Model (GOTM; Umlauf and Burchard, 2005). The hydrodynamic parameters were stored as 2-hourly snapshots.

Hydrodynamic model results for $k_{\mathrm{v}}, \epsilon$ and $\sigma_{\mathrm{T}}$ were linearly interpolated in space and time to extract a corresponding value for every measured data point. Even though stateof-the-art hydrodynamical models generally perform very well, they may locally exhibit discrepancies with observations. To discriminate between profile congruency or the lack thereof, both observed and modeled $\sigma_{\mathrm{T}}$ were interpolated on a common vertical grid of $\Delta z=0.05 \mathrm{~m}$ and filtered by applying a least-square straight line fit to the data and a "natural" cubic spline interpolant. The latter had a weight of $80 \%$ to produce a smooth interpolation curve $\sigma_{\mathrm{T}}^{\prime}\left(z^{\prime}\right)$. Subtracting the respective vertical mean resulted in profiles $\widetilde{\sigma_{\mathrm{T}}}$ for both observed and modeled data. We further constrained our analysis to casts that satisfy two criteria. First, after the subtraction of modeled $\widetilde{\sigma_{T}}$ from observed data, the standard deviation should not exceed $\operatorname{std}\left(\Delta \widetilde{\sigma_{\mathrm{T}}}\right) \leq$ $0.015 \mathrm{~kg} \mathrm{~m}^{-3}$. Second, the density gradients defined as $\delta_{z} \sigma_{\mathrm{T}}=\left(\left\langle\sigma_{\mathrm{T}}^{\prime}\right.\right.$ (last meter $\left.)\right\rangle-\left\langle\sigma_{\mathrm{T}}^{\prime}(\right.$ first meter $\left.\left.)\right\rangle\right) / H$, where $\langle x\rangle$ represents the mean of a variable $x$ and specifically, in this case, the vertical mean, should not exceed a difference of $\Delta \delta_{z} \sigma_{\mathrm{T}} \leq 0.015 \mathrm{~kg} \mathrm{~m}^{-3} \mathrm{~m}^{-1}$ between observed and modeled data. Both limits for $\operatorname{std}\left(\Delta \widetilde{\sigma_{\mathrm{T}}}\right)$ and $\Delta \delta_{z} \sigma_{\mathrm{T}}$ were applied to select similar vertically structured observed and modeled density profiles. The chosen values, however, were somewhat arbitrary and therefore considered in a Monte Carlo-type sensitivity simulation (see below).

ScanFish cruises covered well-mixed coastal but partly also stratified waters in the inner German Bight. A consistent approach to retrieve $w_{\mathrm{s}}$ was required to meet both conditions. When needed, we chose to split casts into subprofiles and to fit the single analytical solution, Eq. (2), to (sub-) profiles. If observed $\delta_{z} \sigma_{\mathrm{T}}<5 \times 10^{-4} \mathrm{~kg} \mathrm{~m}^{-3} \mathrm{~m}^{-1}$, the whole profile was used for fitting, otherwise the cast was split. Since the critical value was set by visual inspection, sensitivity of this critical value was also considered in the Monte Carlo-type simulation described below. Strong gradients in $\sigma_{\mathrm{T}}$ are typically considered to indicate dampening of turbulent mixing. The squared buoyancy frequency $\left(N^{2}\right)$

$N^{2}=\frac{g}{\rho} \frac{\partial \rho}{\partial z}$,

where $g$ denotes the gravitational acceleration constant, is related to the vertical eddy diffusivity $k_{\mathrm{v}}$ by Osborn and Cox (1972):

$k_{\mathrm{v}}=c \frac{\epsilon}{N^{2}}$,

with the current standard value for $c=0.2$ (Lindborg and Brethouwer, 2008). A strong vertical sea water density gradient thus reflects low turbulent diffusion, which would imply spliting profiles in stratified waters at the maximum density gradient(s). However, as recently discussed by Franks (2014), mixed layer depths defined by density gradients are a rather inadequate proxy for turbulence intensity. Since particle properties such as size and density are a function of shear rate and SPM components, it is reasonable to expect them to differ with vertical turbulence intensity, thus leading to different sinking velocities. For example, Leipe et al. (2000) reported vertically varying mean aggregate sizes for the Baltic Sea. While we generally expect vertical gradients in SPMC, strong vertical gradients in SPMC potentially reflect weak mixing and are thus a possible indication for changes in turbulence intensities. The co-occurrence of strong gradients in $\sigma_{\mathrm{T}}$ and SPMC can thus signal changes in turbulence intensity and particle property. Splitting at these points allowed us to apply the analytical SPMC model (Eq. 2), where we assumed a rather homogeneous turbulent diffusion by using the vertically averaged $k_{\mathrm{v}}$. Thus, end points of subprofiles were set, where regions in the profile with

$\left|\frac{1}{C^{\prime}} \frac{\partial C^{\prime}}{\partial z^{\prime}} \cdot \frac{1}{\sigma_{\mathrm{T}}^{\prime}} \frac{\partial \sigma_{\mathrm{T}}^{\prime}}{\partial z}\right|>\left\langle\left|\frac{1}{C^{\prime}} \frac{\partial C^{\prime}}{\partial z^{\prime}}\right|\right\rangle\left\langle\left|\frac{1}{\sigma_{\mathrm{T}}^{\prime}} \frac{\partial \sigma_{\mathrm{T}}^{\prime}}{\partial z}\right|\right\rangle$

occur and reach their maximum. Here, $\langle x\rangle$ denotes the vertical average and $C^{\prime}$ is the SPMC smoothing splineinterpolated analogously to $\sigma_{\mathrm{T}}$. Start points of the subprofiles were either the first data point from the surface or where regions defined by Eq. (5) end with increasing depth. Only subprofiles longer than $4 \mathrm{~m}$ were considered for further analysis.

The analytical model, Eq. (2), was fitted to the original observation of each (sub-) profile with $N_{\mathrm{p}}$ data points, and the cost function

$$
\operatorname{err}=\frac{1}{N_{\mathrm{p}}} \sum_{i=1}^{N_{\mathrm{c}}} \frac{\left(C\left(z_{i}\right)-C_{\mathrm{m}}\left(z_{i}\right)\right)^{2}}{0.5\left(\delta_{\mathrm{R}} C^{2}+\delta_{\mathrm{P}} C^{2}\right)}
$$




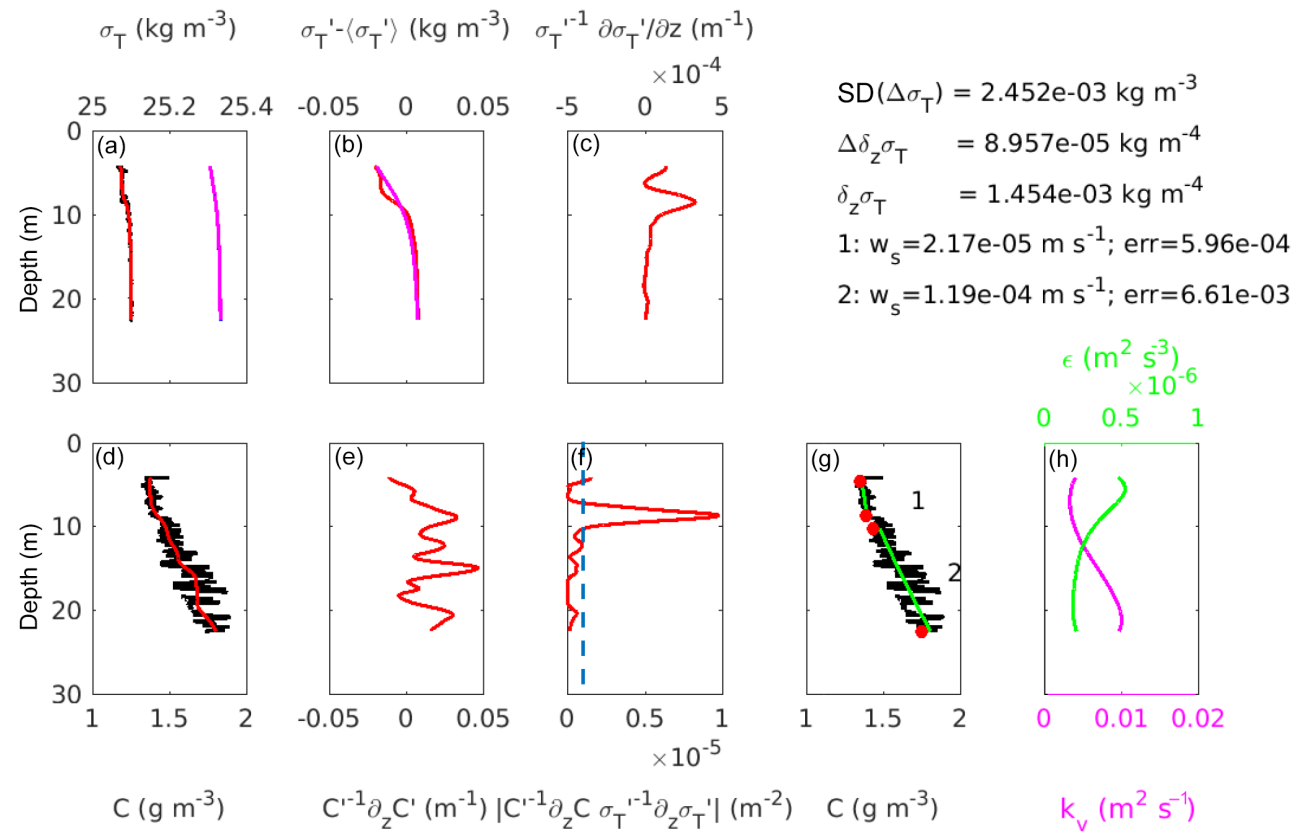

Figure 2. Example for the (a) spline-fitted profiles, (b) comparison between observed and modeled spline-fitted $\sigma_{\mathrm{T}}^{\prime}$, (c-g) the splitting and subsequent fitting of the analytical model to vertical SPMC subprofiles; derived $w_{\mathrm{s}}$ and analytical model errors (Eq. 6) are given by the corresponding numbers. (h) Turbulence model-calculated $\epsilon$ (green) and $k_{\mathrm{V}}$ (magenta) profile. For (a-g) lines in black: raw observations; red: spline fits; magenta: hydrodynamical spline fits; blue dashed line in (f) critical depth-averaged value (right-hand side of Eq. 5); green: analytical model fit; red dots: derived split points from Eq. (5).

was calculated accordingly. $\delta_{\mathrm{P}} C^{2}$ and $\delta_{\mathrm{R}} C^{2}$ represent the variance in concentration of a profile and in a region, respectively. The latter was defined as the variance for measurements around the profile within \pm 5 min to account for higher variability in coastal than in open-water regions found in a pre-analysis of the data. Only profiles below a cost function value of 0.05 , chosen by visual inspection, were considered for the analysis. The splitting and subsequent fitting of the analytical model is visualized in Fig. 2. The variables SPMC and fluorescence-to-SPMC ratio (F / SPMC) were vertically averaged for the respective (sub-) profiles. Afterward, variables were binned with respect to modeled $\epsilon$ and eventually averaged bin-wise, resulting in respective bin-wise ensemble means $\langle$ SPMC $\rangle,\langle\mathrm{F} / \mathrm{SPMC}\rangle,\left\langle w_{\mathrm{s}}\right\rangle$ and $\langle\epsilon\rangle$. To test for significant changes in binned $\left\langle w_{\mathrm{s}}\right\rangle$ with $\langle\epsilon\rangle$, we applied a MannWhitney $U$ test with a significance level of $p<0.05$ for each binned $\left\langle w_{\mathrm{s}}\right\rangle$ against each other. In summary, approximately $67 \%$ of the $\approx 68000$ profiles initially measured passed the congruency check with modeled ones. After the application of the cost function threshold, this resulted in about 12260 $w_{\mathrm{s}}$ values.

All applied threshold values were carefully selected by visual inspection during each filtering step. To quantify their influence on the result, we performed a Monte Carlo-type simulation with a variation of $\pm 50 \%$ for the following parameters: $\operatorname{std}\left(\Delta \widetilde{\sigma_{T}}\right), \Delta \delta_{z} \sigma_{\mathrm{T}}, \delta_{z} \sigma_{T}$ and the cost function error. The analysis was repeated for variations of all parame- ters against each other. For each parameter variation, binned mean values for $\left\langle w_{\mathrm{s}}\right\rangle$ vs. $\epsilon$ were calculated and are then averaged and their standard deviation $\sigma$ quantified (see Fig. 4c).

\subsection{Conceptual cross-coastal sinking velocity model}

We introduce and apply a conceptual model for the crossshore variation of $w_{\mathrm{s}}$ as a tool to interpret our results. According to Stokes (1851), $w_{\mathrm{s}}$ of a particle of diameter $D$ can be described by

$w_{\mathrm{s}}=\frac{1}{18 \mu}\left(\rho_{\mathrm{f}}-\rho\right) g D^{2}$,

where $\mu$ is the dynamic viscosity, $\rho$ is the water density and $g$ the gravitational acceleration constant. The floc density $\rho_{\mathrm{f}}$ is strongly related to the particles' composition and structure. The latter can be described as fractal dimension $d_{\mathrm{f}}$ according to Kranenburg (1994), who derived the excess floc density $\Delta \rho_{\mathrm{f}}=\rho_{\mathrm{f}}-\rho$ for a particle composed of primary particles of diameter $D_{\mathrm{p}}$ and density $\rho_{\mathrm{p}}$ :

$\Delta \rho_{\mathrm{f}}=\left(\rho_{\mathrm{p}}-\rho\right)\left(\frac{D_{\mathrm{p}}}{D}\right)^{3-d_{\mathrm{f}}}$.

Following the approach of Kranenburg (1994) and assuming equally sized primary particles of diameter $D_{\mathrm{p}}$, Maggi (2009) derived the excess floc density for an aggregate composed of mineral and organic particles with density $\rho_{\mathrm{s}}$ and $\rho_{\mathrm{o}}$, respectively: 
$\Delta \rho_{\mathrm{f}}=\left(\omega \Delta \rho_{\mathrm{s}}+(1-\omega) \Delta \rho_{\mathrm{o}}\right) \cdot\left(\frac{D_{\mathrm{p}}}{D}\right)^{3-d_{\mathrm{f}}}$.

For $w_{\mathrm{s}}$ of an aggregate, it follows

$w_{\mathrm{s}}=\frac{1}{18 \mu}\left(\omega \Delta \rho_{\mathrm{s}}+(1-\omega) \Delta \rho_{\mathrm{o}}\right) g D_{\mathrm{p}}^{3-d_{\mathrm{f}}} D^{d_{\mathrm{f}}-1}$,

where $\omega=n_{\mathrm{s}} /\left(n_{\mathrm{S}}+n_{\mathrm{o}}\right)$ and $n_{\mathrm{S}}$ and $n_{\mathrm{o}}$ are the number of mineral and organic primary particles, respectively.

This simple $w_{\mathrm{s}}$ model, Eq. (10), allows the calculation of trends in $w_{\mathrm{s}}$ on a cross-shore transect. Based on observations, we presume the general following parameter changes from coastal to open waters: (i) average primary particle size and aggregate size increase, (ii) particles become more organic, and (iii) particles become more porous; thus, $d_{\mathrm{f}}$ decreases. Based on a first-order approach, we assume a linear decrease or increase in parameters with distance from coast. For boundary conditions in coastal waters, we therefore assume an average $\left\langle D_{\mathrm{p}}\right\rangle=4 \mu \mathrm{m}$ due to the dominance of cohesive sediment (Winterwerp, 1998), $\langle D\rangle=100 \mu \mathrm{m}$ (Fettweis et al., 2006), $\omega=0.9$ to account for a loss on ignition (LoI) of $\approx 0.04$ (Fettweis, 2008) and $d_{\mathrm{f}}=2.0$ as an average coastal fractal dimension (Winterwerp, 1998). By contrast, for open waters we presume the following: $\left\langle D_{\mathrm{p}}\right\rangle=10 \mu \mathrm{m}$ for algaedominated particles; $\langle D\rangle=500 \mu \mathrm{m}$ since we assume similar trends as in van der Lee et al. (2009) for the Irish Sea; $\omega=0.05$, to parallel a LoI $\approx 0.89$ (Eisma and Kalf, 1987); and $d_{\mathrm{f}}=1.6$ as a typical value for fluffy aggregates (Logan and Alldredge, 1989; Li and Logan, 1995). The densities of primary particles are set to $\rho_{\mathrm{p}}=2650 \mathrm{~kg} \mathrm{~m}^{-3}$ (Maggi, 2009) and $\rho_{\mathrm{o}}=1100 \mathrm{~kg} \mathrm{~m}^{-3}$, which is computed as an average of the range given in Fettweis (2008). The water density and the dynamic viscosity are set to $\rho=1000 \mathrm{~kg} \mathrm{~m}^{-3}$ and $\mu=0.001 \mathrm{~kg} \mathrm{~m}^{-1} \mathrm{~s}^{-1}$, respectively. The sensitivity of $w_{\mathrm{s}}$ to changes in each parameter is assessed by varying each parameter separately while keeping the other parameters at their typical values for coastal waters; e.g., for an organicrich aggregate with an assumed diameter of $D=100 \mu \mathrm{m}$ and $\omega=0.5, D_{\mathrm{p}}=4 \mu \mathrm{m}$ and $d_{\mathrm{f}}=2$.

\section{Results}

\subsection{Cross-coastal gradients}

Energy dissipation rates $\epsilon$ generally possess spatiotemporal variability. Most relevant for this study, vertically and temporally averaged model-derived $\epsilon$ exhibits a cross-shore gradient from the inner German Bight towards the coast. The temporal averaging is carried out for the time of the cruises while accounting for the length of the tidal cycle. Values range between $\epsilon \approx 10^{-9} \mathrm{~m}^{2} \mathrm{~s}^{-3}$ and $\epsilon \approx 10^{-4} \mathrm{~m}^{2} \mathrm{~s}^{-3}$ (Fig. 3).

In this range, mean SPMC first increases from values below $1 \mathrm{~g} \mathrm{~m}^{-3}$ to approximately $10 \mathrm{~g} \mathrm{~m}^{-3}$. Above $\log _{10}(\epsilon)=$

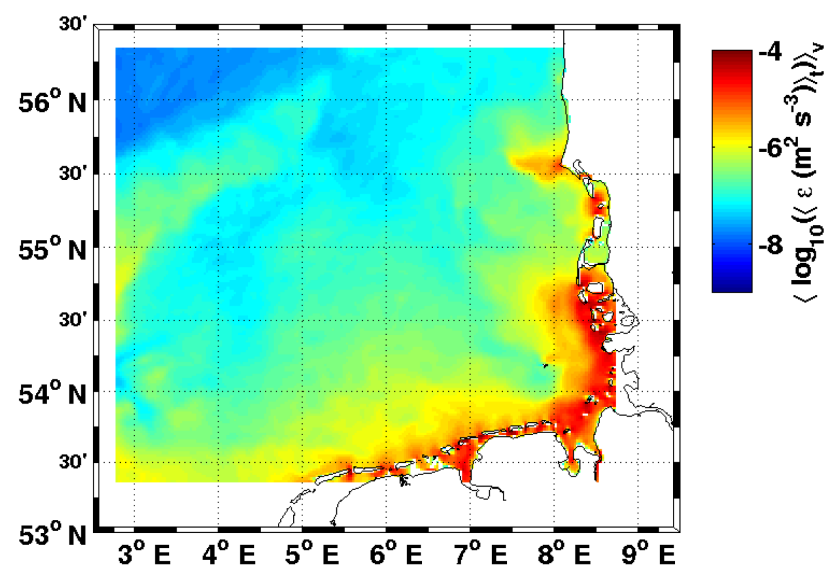

Figure 3. Map of hydrodynamic model-calculated time- and depthaveraged energy dissipation rate $\epsilon$ for the times of the cruises.

-5.5 , mean SPMC moderately decreases to approximately $6 \mathrm{~g} \mathrm{~m}^{-3}$ and increases again to $10 \mathrm{~g} \mathrm{~m}^{-3}$ with a further increase in $\epsilon$ (Fig. 4a) towards the coast.

Under the assumption that fluorescence can be applied as a proxy for POM, the potential significance of algae and their products for particle composition is depicted by the mean ratio between measured fluorescence and SPMC. High F / SPMC ratios indicate rather organic-rich particles, while low F / SPMC ratios indicate rather mineral particledominated flocs. The F / SPMC ratio shows rather high variability for $\log _{10}(\epsilon)<-6$ (Fig. 4b). With a further increase in $\epsilon$, the ratio drops and levels at approximately a fourth of the open German Bight value for $\log _{10}(\epsilon)>-5$.

Average sinking velocities $\left\langle w_{\mathrm{s}}\right\rangle$ show very low values of the order of $10^{-6}$ to $10^{-5} \mathrm{~m} \mathrm{~s}^{-1}$ in regions of $\log _{10}(\epsilon)<-7.5$ (Fig. 4c). At higher $\epsilon,\left\langle w_{\mathrm{s}}\right\rangle$ increases significantly reaching a maximum of about $7 \times 10^{-4} \mathrm{~m} \mathrm{~s}^{-1}$ around $\log _{10}(\epsilon) \approx-5.5$. This maximum $\left\langle w_{\mathrm{s}}\right\rangle$ around $\log _{10}(\epsilon) \approx$ -5.5 coincides with an increase in SPMC and a drop in fluorescence to SPMC ratio. By further increasing $\epsilon,\left\langle w_{\mathrm{s}}\right\rangle \mathrm{de}$ creases again to values of $\left\langle w_{\mathrm{s}}\right\rangle \approx 3 \times 10^{-4} \mathrm{~m} \mathrm{~s}^{-1}$. The Monte Carlo-type simulation to estimate parameter uncertainties exhibits the same pattern, expressed as $\sigma$ and $2 \sigma$ confidence levels (68\% and $95 \%$, respectively; Fig. $4 \mathrm{c}$ ) around their ensemble mean and thus underpins the results of $\left\langle w_{\mathrm{s}}\right\rangle$ along $\epsilon$.

\subsection{Conceptual model}

The sinking velocity of an average particle (as parametrized in Sect. 2.4) changes almost linearly with variations of single parameters from open to coastal waters (Fig. 5, upper four panels). Flocs would sink less rapidly because of the decreasing diameter of the aggregate or primary particles in the coastal region. By contrast, increasing amounts of mineral particles and fractal dimension would both lead to increased $w_{\mathrm{s}}$. As an overall effect, when considering all parameters, 

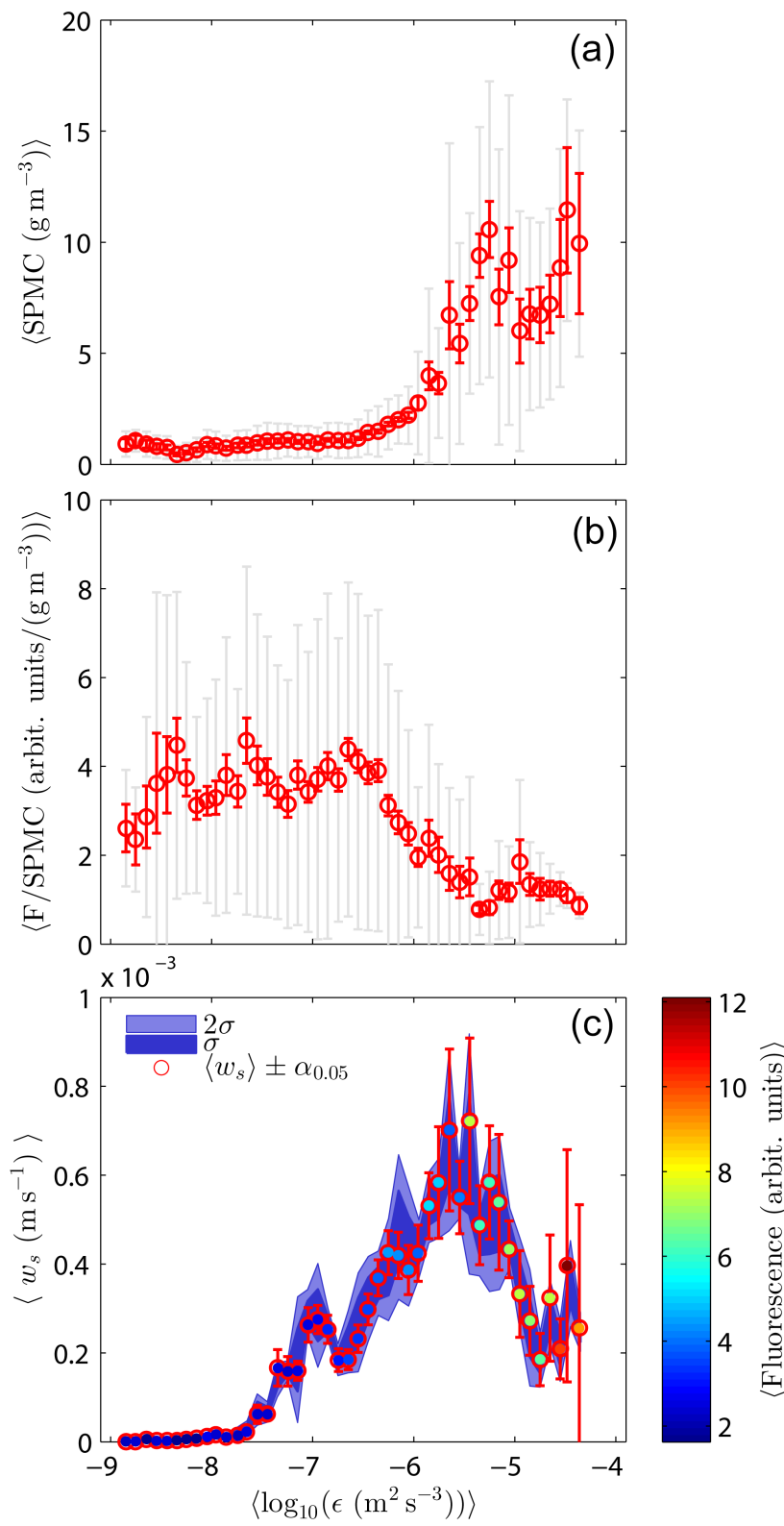

Figure 4. (a) $\langle\mathrm{SPMC}\rangle$, (b) $\langle\mathrm{F} / \mathrm{SPMC}\rangle$ ratio and (c) $\left\langle w_{\mathrm{s}}\right\rangle$ vs. $\left\langle\log _{10}\left(\epsilon\left(\mathrm{m}^{2} \mathrm{~s}^{-3}\right)\right)\right\rangle$. Gray error bars represent the standard deviation and red error bars represent the confidence intervals $(\alpha-$ quantile $=0.05$ ) for the averages in each bin. Average values for the bins were used for the color coding. In (c) $\sigma$ and $2 \sigma$ represent the confidence levels of 68 and $95 \%$, respectively, for the Monte Carlo-type parameter variation.

$w_{\mathrm{s}}$ reaches a maximum in between the nearshore and open waters (lowest panel of Fig. 5).

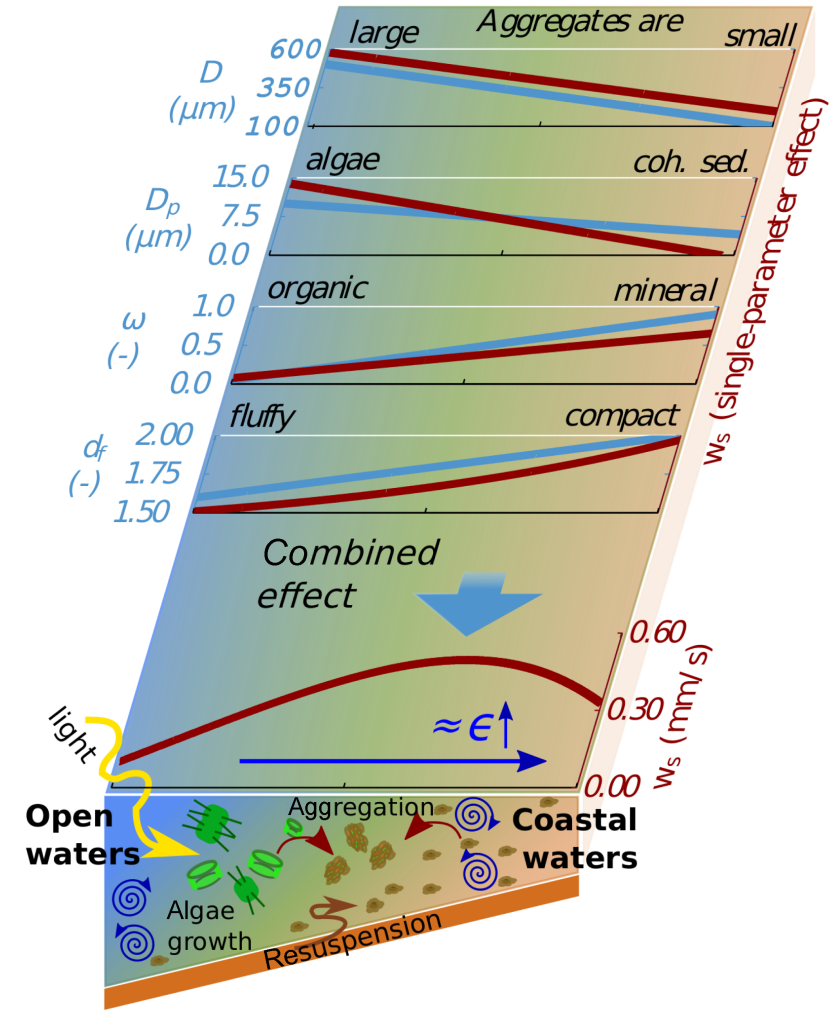

Figure 5. Schematic view of potential influences on sinking velocity (red lines) from open waters (left) to coastal waters (right) and the changing parameters' total impact on the resulting sinking velocity (lowest panel) calculated according to Eq. (10). The sinking velocities shown in the upper four panels are based on a particle of $D=100 \mu \mathrm{m}, \omega=0.5, D_{\mathrm{p}}=4 \mu \mathrm{m}$ and $d_{\mathrm{f}}=2$, while the respective parameter shown in the panel is varied (blue lines) (constant parameters are $\mu=0.001 \mathrm{~kg} \mathrm{~m}^{-1} \mathrm{~s}^{-1}, \rho=1000 \mathrm{~kg} \mathrm{~m}^{-3}$, $\rho_{\mathrm{o}}=1100 \mathrm{~kg} \mathrm{~m}^{-3}$ and $\rho_{\mathrm{s}}=2650 \mathrm{~kg} \mathrm{~m}^{-3}$ ).

\section{Discussion}

\subsection{Sinking velocity on a gradient of prevailing energy dissipation rate}

Sinking velocities were determined along a cross-shore transect in the German Bight defined by the prevailing $\epsilon$. For the reconstruction of $\left\langle w_{\mathrm{s}}\right\rangle$, we had to assume congruency between in situ measurements and hydrodynamic model results within a range defined by the applied filters. The estimated $\left\langle w_{\mathrm{s}}\right\rangle$ of the order of $10^{-6}$ to $5 \times 10^{-4} \mathrm{~m} \mathrm{~s}^{-1}$ in low- and highenergy dissipation regions, respectively (Fig. 4), compare very well with previous in situ studies in the German Bight and adjacent areas. Puls et al. (1995) found $w_{\mathrm{s}} \approx 10^{-6} \mathrm{~m} \mathrm{~s}^{-1}$ to $2 \times 10^{-5} \mathrm{~m} \mathrm{~s}^{-1}$ for the open German Bight, a low- $\epsilon$ region, and Pejrup and Mikkelsen (2010) reported median $w_{\mathrm{s}}$ of $1 \times 10^{-4}$ to $11 \times 10^{-4} \mathrm{~m} \mathrm{~s}^{-1}$ for the Rømø and Højer Dyb, Danish Wadden Sea, where $\epsilon$ is comparably high. Our estimated $\left\langle w_{\mathrm{s}}\right\rangle$ is also well within the range found in other re- 


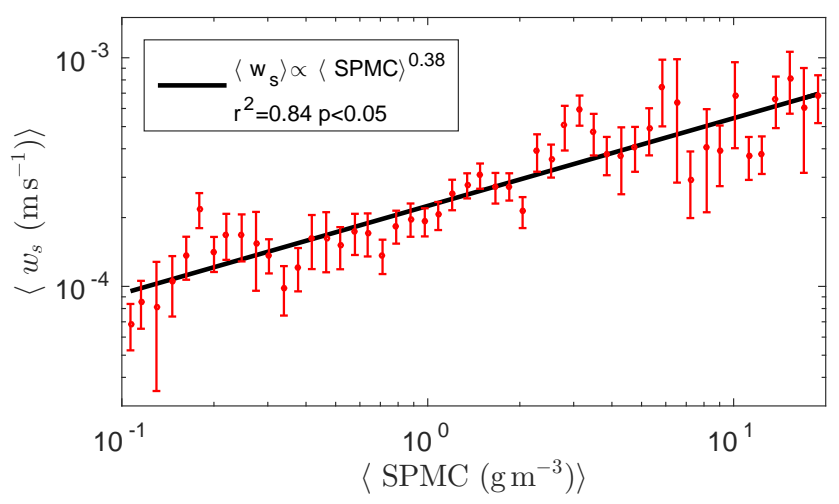

Figure 6. Scatterplot of $\langle$ SPMC $\rangle$ and $\left\langle w_{\mathrm{S}}\right\rangle$. Error bars represent the confidence intervals $(\alpha-$ quantile $=0.05)$ for the averages in each bin. The rather poor correlation can be attributed to the heterogeneity of the German Bight system. See text for discussion.

gions, e.g., in Chesapeake Bay (Gibbs, 1985) or at the Belgian coast (Fettweis and Baeye, 2015). In agreement with previous studies (e.g., compiled in Dyer, 1989), $\left\langle w_{\mathrm{s}}\right\rangle$ increases with increasing $\langle\mathrm{SPMC}\rangle$ (Fig. 6), which gives further confidence in the methodological approach. However, the correlation is rather poor compared to previous local studies and can be explained by the heterogeneity of the German Bight system, seasonal effects and the intrinsically high variability of sinking velocities (Fettweis, 2008) and of turbulence (Pejrup and Mikkelsen, 2010). The significant maximum of $\left\langle w_{\mathrm{s}}\right\rangle$ at $\langle\epsilon\rangle \approx 10^{-5.5} \mathrm{~m}^{2} \mathrm{~s}^{-3}$ can be explained by the balance between aggregation and fragmentation. Both processes are controlled by turbulent shear that is generated by energy dissipation, SPM volume concentration and adhesion properties of the particles involved. Previous flocculation modeling studies point to a formation of $w_{\mathrm{s}}$ maximum along $\epsilon$ (Winterwerp, 1998; Pejrup and Mikkelsen, 2010). Our findings of a maximum $\left\langle w_{\mathrm{s}}\right\rangle$ between $\epsilon \approx 10^{-6}$ and $10^{-5} \mathrm{~m}^{2} \mathrm{~s}^{-3}$, which translates to shear rates of about $1-3.2 \mathrm{~s}^{-1}$ for $v=$ $10^{-6} \mathrm{~m}^{2} \mathrm{~s}^{-1}$, should thus be comparable to previous theoretical studies. For example, in a field-work-based modeling approach, Pejrup and Mikkelsen (2010) found the maximum of sinking velocity to occur under higher shear rates of about $8.5 \mathrm{~s}^{-1}$. By contrast, Maerz et al. (2011) calculated highest mean sinking velocities of about $5 \times 10^{-4} \mathrm{~m} \mathrm{~s}^{-1}$, similar to our findings, for a jar test device-based laboratory experiment with natural SPM at shear rates of about $1 \mathrm{~s}^{-1}$. Given the underlying uncertainties in calculating the shear rate in both cases, our study agrees well with previous theoretical studies. Hence, as suggested by Dyer (1989) and Pejrup and Mikkelsen (2010), in addition to SPMC, turbulent shear can be regarded as the major determinant for $w_{\mathrm{s}}$.

\subsection{Sinking velocity as a result of SPMC, composition and a turbulence gradient}

Our study additionally suggests a change in particle composition, with $\epsilon$ as proxied by the fluorescence-to-SPMC ratio. With $\epsilon$, SPMC increases towards the coast and the mineral fraction becomes dominant compared to organic particles at low $\epsilon$ (Eisma and Kalf, 1987). Hence, density and other physicochemical properties of primary particles such as size and adhesion can change accordingly and thus influence $w_{\mathrm{s}}$ along a cross-shore transect. Our conceptual model illustrates the effect of varying particle properties on $w_{\mathrm{s}}$ independent of the observations used in our data analysis. However, the course of the parameters implicitly presumes certain environmental conditions, such as particle size being, among other factors, a function of SPMC and shear. Singleparameter changes in the conceptual model result in mostly linear responses in $w_{\mathrm{s}}$, while considering all parameters leads to a maximum in $w_{\mathrm{s}}$ on the conceptual cross-shore transect, in agreement with our findings in the data analysis. The assumption of linearly changing parameters is a first-order approximation. Different and nonlinear changes in parameters would lead to a transformation of the maximum sinking velocity zone such as a shifting and/or stretching (not shown). Previous model studies show that for a given shear regime, varying particle properties such as particle adhesion can lead to a change in particle size and thus sinking velocity (e.g., Maerz et al., 2011). Hence, higher particle adhesion would translate to larger particles and stronger fragmentation resistance, which would allow particles to sink out of the water column closer to the coast under higher turbulence intensity. This implies that spatial changes in SPMC and composition, and accordingly physicochemical properties of particles, potentially affect the location of the transition zone. As discussed below, this probably happens on a seasonal timescale due to the modulation of the transition zone by phytoplankton exudations, which requires further investigations. While the cross-shore distribution of $w_{\mathrm{s}}$ is predominantly controlled by prevailing shear, the conceptual model indicates a potential additional relevance of physicochemical properties for the formation of the high-sinking velocity zone.

\subsection{Implications of a cross-coastal maximum of sinking velocity for biogeochemical cycling in the coastal zone}

The region of $\log _{10}(\epsilon) \approx-5.5$ with highest $\left\langle w_{\mathrm{s}}\right\rangle$ coincides with a zone located off the coast at a depth of about 15 to $20 \mathrm{~m}$. It is accompanied by a strong gradient in SPMC and SPM composition that is depicted by the F/ SPMC ratio. This suggests that the region can be considered a transition zone, hindering mineral particles from escaping further offshore. To simplify this, consider the course from the coast to open waters. Once formed, relatively dense fast-sinking flocs, whose properties are adapted to the transition zone tur- 
bulence level, would easily settle out of the water column when transported offshore. This is because turbulence becomes too weak to break those aggregates apart and to retain them in suspension. Thus, only loose, organic-rich particles are kept suspended in the water column while mineral-rich particles tend to settle out of the water column. Such trapping is previously described conceptually for other regions, e.g., by Mari et al. (2012) and Ayukai and Wolanski (1997) for river plumes. High $\left\langle w_{\mathrm{s}}\right\rangle$ in the transition zone thus implies an enhanced link between pelagic and near-bottom processes. Among them, different transport mechanisms are discussed in the literature that potentially lead, on average, to a net transport of fine sediments shorewards into the tidal back barriers. Settling lag is caused by the different time durations for particles to sediment in different water depths after the bottom shear stress for erosion falls below the critical stress (Postma, 1961). Another process is scour lag, which potentially arises from needing lower bottom shear stresses to keep particles in suspension than for their erosion in combination with an asymmetry in the flow (Van Straaten and Kuenen, 1957). These effects are investigated under different topographical settings (van Maren and Winterwerp, 2013), and the authors concluded that $w_{\mathrm{s}}$ in the range of 0.5 and $1 \mathrm{~mm} \mathrm{~s}^{-1}$ leads to the highest deposition rates and underlined the necessity of fine mineral particle flocculation for the buildup of tidal flat systems. Recently, another potential major driver, the estuarine circulation, has been suggested for sediment accumulation in the Wadden Sea. Residual currents of the estuarine circulation are driven by density gradients that can be caused by (i) horizontal temperature gradients, (ii) differential precipitation, (iii) river discharges and (iv) all possible superpositions. Residual currents of the estuarine circulation flow shorewards in near-bottom waters and offshore in surface waters (Burchard et al., 2008; Flöser et al., 2011). This probably causes a net SPM flux into the Wadden Sea (Burchard et al., 2008, 2013). The Wadden Sea is hypothesized to act as bioreactor, where organic components of SPM become remineralized and are exported in dissolved form (Postma, 1984; Ebenhöh et al., 2004; Grunwald et al., 2010) by the offshore-directed component of the estuarine circulation. Along this pathway, dissolved nutrients are assimilated by phytoplankton and thus transferred to bio particulates. This is likely to happen particularly within the region of prevailing $\epsilon \approx 10^{-5.5} \mathrm{~m}^{2} \mathrm{~s}^{-3}$, where phytoplankton experience favorable growth conditions as found by Pingree et al. (1978) for different places on the northern European continental shelf. Algae exude EPSs like TEPs that can undergo and mediate flocculation by bridging and embedding minerals. The mineral particles ballast the organic matrix and lead to enhanced sinking velocities, as previously described for the deep ocean (Passow, 2004; De La Rocha and Passow, 2007), which again links pelagic processes to the residual near-bottom currents of the estuarine circulation. In summary, this would imply that the transition zone characterized by its high $\left\langle w_{\mathrm{s}}\right\rangle$ accompanied with strong SPMC gra- dients acts as an important off-coastal feature for closing the nearshore nutrient and mineral cycle. Such a biologically mediated trapping mechanism would retain nutrients and minerals in the coastal zone and inside the Wadden Sea back barriers.

\subsection{Spatial biogeochemical implications of a coastal transition zone}

Typically, spatial information on biochemical variables are needed to better understand system-wide cycling and the fate of matter. Unfortunately, averaging of $w_{\mathrm{s}}$ over bins of $\epsilon$ means a possible loss of direct spatial reference. However, our approach made it possible to identify a general pattern of $\left\langle w_{\mathrm{s}}\right\rangle$ with a defined maximum along prevailing energy dissipation rates. Even though we neither resolve tidal cycles nor consider potential seasonal variation of $\left\langle w_{\mathrm{s}}\right\rangle$ along $\langle\epsilon\rangle$, a map of $\left\langle w_{\mathrm{s}}\right\rangle$ allows insights into the spatial distribution and variability of $\left\langle w_{\mathrm{s}}\right\rangle$. It is reconstructed by mapping the bin-wise relationship found between $\langle\epsilon\rangle$ and $\left\langle w_{\mathrm{s}}\right\rangle$ (Fig. 4c) onto the respective spatial $\langle\epsilon\rangle$ (Fig. 3). It must be highlighted that local, short-term in situ measurements would most likely deviate from the obtained averaged picture (Fig. 7) that would be challenging to derive by in situ measurements. Nevertheless, strong spatial variability is visible with a pronounced crossshore gradient of $\left\langle w_{\mathrm{s}}\right\rangle$ featuring a maximum of sinking velocities along the coastline as indicated before. However, this maximum varies locally and is particularly less pronounced at the northern German and southern Danish coast, where $\left\langle w_{\mathrm{s}}\right\rangle$ declines to values that are in the range of $\left\langle w_{\mathrm{s}}\right\rangle$ in deeper waters in the southern German Bight. Applying the aforementioned concept of the transition zone as an off-coastal closing mechanism for nutrient cycling to the two contrasting German Wadden sea regions - East Frisian Wadden Sea and North Frisian Wadden Sea (particularly the Sylt-Rømø Bight) - may help to better understand regional differences in nutrient concentrations. Lower nutrient concentrations and thus lower eutrophication levels in the Sylt-Rømø Bight compared to the East Frisian Wadden Sea are regularly observed (van Beusekom et al., 2009). In this case, the maximal $\left\langle w_{\mathrm{s}}\right\rangle$ calculated in front of the Sylt-Røm $\varnothing$ tidal inlet amounts only to $4 \times 10^{-4} \mathrm{~m} \mathrm{~s}^{-1}$, about half the magnitude found off the other Wadden Sea regions. Hence, the ability to retain nutrients is diminished and would contribute to the lower nutrient concentrations compared to other Wadden Sea regions. By contrast, the potentially pronounced retention capacity of the transition zone, as predicted for the Dutch coast and German East Frisian islands, may contribute to the phenomenologically described line of no return (Postma, 1984), expected further off the coast and characterized by low SPMC. The spatial distribution of $\left\langle w_{\mathrm{s}}\right\rangle$ is probably also reflected in the SPMC and their cross-coastal gradients (Fig. 8). Flocs with high $w_{\mathrm{s}}$ are likely mineral-dominated and would rapidly sink out of the water column and thus lead to strong crosscoastal diminishing of SPMC. Generally, dilution of SPMC 


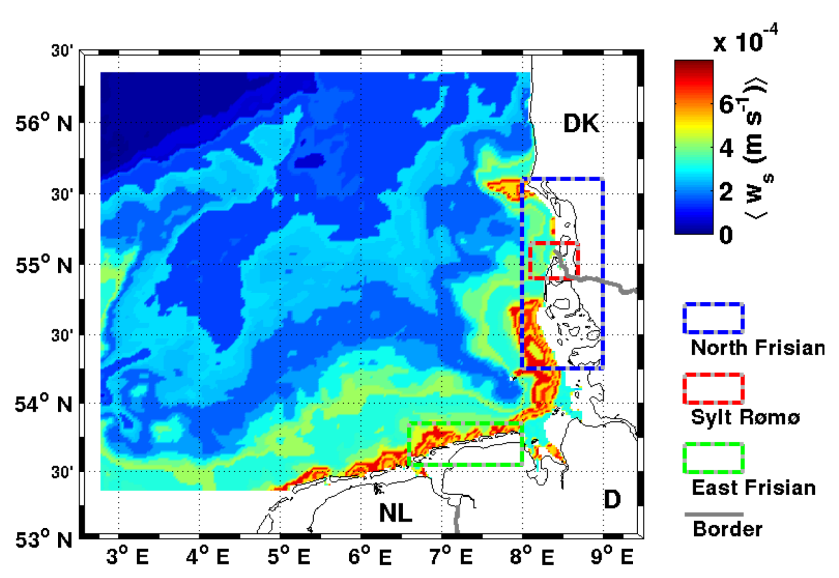

Figure 7. Map of spatial distribution of $\left\langle w_{\mathrm{s}}\right\rangle$ in the German Bight. Results for $\left\langle w_{\mathrm{s}}\right\rangle$ from Fig. 4 were mapped onto the modeled $\langle\epsilon\rangle$ shown in Fig. 3 to provide spatial information on potentially prevailing $\left\langle w_{\mathrm{s}}\right\rangle$. Areas of water depth smaller than $5 \mathrm{~m}$ are not considered.

occurs due to cross-shore wise increasing water depth and local currents parallel to the coast potentially confining horizontal SPMC distribution to the near-coast region (Staneva et al., 2009). Nevertheless, on average, lower $\epsilon$ accompanied by lower SPMC and smaller horizontal gradients is found along the North Frisian than along the Dutch and East Frisian coast (Figs. 3 and 8). In combination, these conditions, in particular along the Sylt-Rømø islands, suppress the establishing of a defined transition zone. Hence, lower $w_{\mathrm{s}}$ should be found as implied by Fig. 7. As a result, retention efficiency is likely reduced and potentially contributes to the observed lower nutrient concentrations compared to the East Frisian Wadden Sea (van Beusekom et al., 2009).

Other concepts are presented to explain the observed spatial heterogeneity of eutrophication levels along the Wadden Sea coast. These explanations are categorized into two main groups by van Beusekom et al. (2012): either according to (i) regional differences in organic matter import or (ii) differences in the size of the tidal basins. Potential differences of the import amount were attributed to different (i) regional offshore primary production, (ii) orientation of the coastline with respect to dominant wave and current directions, and (iii) intensity of shoreward bottom currents. The eutrophication status can be related to the tidal basin width, where narrow tidal basins have a higher eutrophication status than wider ones (van Beusekom et al., 2012). While the general buildup of nutrient gradients towards the coast is attributed to the above discussed processes of settling and scour lag in combination with the estuarine circulation, no clear mechanistic explanation is given as to why the size of the tidal basins lead to the relation found. van Beusekom et al. (2012) suggested that POM imported into the tidal basins would be either distributed over a larger area for wide basins, which would lead to gentle nutrient gradients compared to steeper
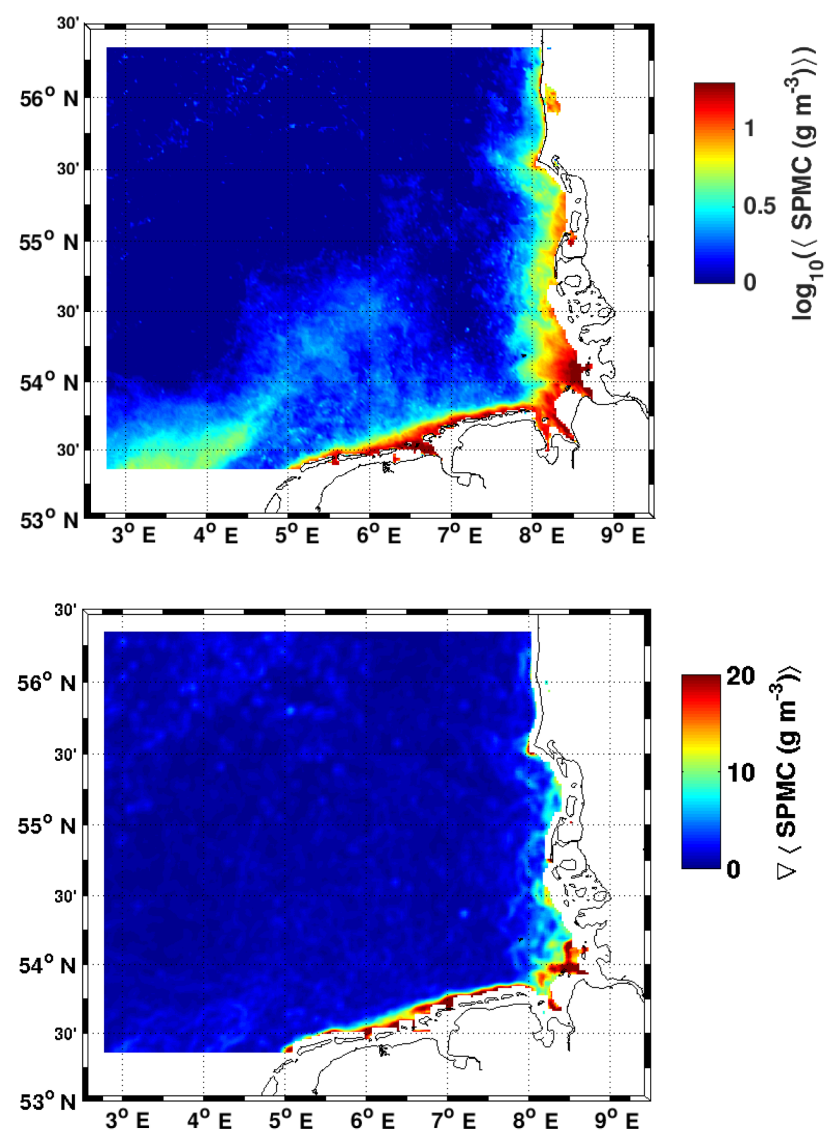

Figure 8. Top: MERIS-derived temporally averaged SPMC in the German Bight. Averaging of available MERIS scenes was carried out for the times of the cruises. Regions of water depths smaller than $5 \mathrm{~m}$ were whited out. Bottom: pixel-wise gradients of SPMC calculated by $\left(\left(\partial_{x}\langle\text { SPMC }\rangle\right)^{2}+\left(\partial_{y}\langle\text { SPMC }\rangle\right)^{2}\right)^{1 / 2}$, where $x$ and $y$ are east-west and south-north pixel directions, respectively. A Wiener filter of three by three pixels was subsequently applied. Notice the stronger gradients along the Dutch and East Frisian coastline compared to the North Frisian coast with the Sylt-Rømø Bight at $55^{\circ} \mathrm{N}$. For regions, see also Fig. 7.

nutrient gradients in narrower basins. However, other explanations cannot be ruled out, e.g., those linked to differences in water exchange times (van Beusekom et al., 2012). It is likely that a multitude of processes interact, and detailed modeling studies are required to disentangle their relative contributions to the observed spatial heterogeneity of the Wadden Sea eutrophication status. Noticeably, the Sylt basin exhibits exceptionally low eutrophication status in the study of van Beusekom et al. (2012), which would fit into the picture that the import of POM is reduced due to the rather weakly established transition zone in this area.

Since the driving mechanisms behind the transition zone are probably ubiquitous for coastal marine systems with sufficiently strong cross-shore water density gradients generated by freshwater runoff, precipitation-evaporation balance 
or heat fluxes, local hydrodynamics will determine its eventual formation. This implies that the concept of the transition zone with its retention capacity for nutrients may be applicable to other coastal marine and estuarine systems in general and will help to better understand different nutrient cycling behavior among those systems.

\subsection{Biological modulation of the transition zone?}

There is increasing evidence that sticky algae excretions such as transparent exopolymer particles mediate aggregation and increase shear resistance of particles to fragmentation, potentially enabling algae to clear the water column from mineral load (Fettweis et al., 2014). As shown in the conceptual model (Sect. 2.4), high $w_{\mathrm{s}}$ occurs due to the interplay of shear-driven flocculation and primary particle density and size. Similarly, Hamm (2002) found a nonlinear effect of the ratio of mineral-organic weight to weight content on sinking velocity showing first an increasing $w_{\mathrm{s}}$ for increasing mineral load but a stagnation or even converse effect when exceeding a certain threshold. To hypothesize, a high concentration of SPM with an optimal ratio between dense mineral and sticky bio particles might exist in the transition zone under favorable turbulent conditions to form larger flocs compared to near-coast regions and denser flocs compared to open waters. In sum, this could lead to the high $\left\langle w_{\mathrm{s}}\right\rangle$ found. This raises the important question as to what extent algae can affect the transition zone and its seasonal location to sustain the effective coastal nutrient cycle that is driven by the estuarine circulation. By sustaining the nutrient cycle, algae potentially support the development of the pronounced nutrient gradients towards the Wadden Sea. As a consequence, 3-D biogeochemical models require a representation of the tight coupling between sediment dynamics and biogeochemical, potentially even adaptive phytoplankton physiological processes to improve models' capability to estimate particulate matter fluxes.

\section{Conclusions}

The present study provides a strong indication of a maximum of sinking velocities along a cross-shore transect that is defined by a gradient of prevailing energy dissipation rates. Towards the offshore areas, the enhanced sinking velocities are accompanied by a strong decline in SPMC and an increasing $\mathrm{F} / \mathrm{SPMC}$ ratio. The interplay of processes leading to the observed features defines the region as a coastal transition zone. In turn, processes feed back to SPMC and composition.

The transition zone is probably an important feature on the course from the coast to the continental shelf. Predominantly driven by turbulent shear generated by energy dissipation, the transition zone with the highest sinking velocities potentially acts as a retention zone for dissolved nutrients leaking from nearshore waters by providing favorable conditions for algae growth. Phytoplankton take up nutrients and excrete EPSs that mediate flocculation processes. Embedding minerals in the organic matrix leads to enhanced sinking velocities. Algae thus seem to possess the ability to clear the water column (Fettweis et al., 2014) and link the offshore dissolved nutrient fluxes to residual landward bottom fluxes. Consequently, these interlinked processes would have the potential to retain fine sediments and nutrients in coastal areas. The strength of the links eventually affects the eutrophication state of the coastal region.

It is scarcely understood what relevance individual processes have in forming the transition zone. Besides favoring energy dissipation rates of about $\epsilon \approx 10^{-5.5} \mathrm{~m}^{2} \mathrm{~s}^{-3}$, algae and their extracellular polymeric excretions are potentially important in forming the transition zone as EPSs are known to enhance collision efficiency and resistance to fragmentation. Since primary production in the studied area features a pronounced seasonal cycle, further studies are thus needed to investigate the temporal and spatial extension of the transition zone. Long-term or repeated spatial in situ measurements, including SPMC, $\epsilon$ profiles and particle properties such as size, $w_{\mathrm{s}}$ and (volume) composition, are required to underpin the enhanced sinking velocities found indirectly as a feature of the transition zone. Additionally, modeling approaches are required to gain a deeper processbased understanding and to disentangle the closely linked processes among other eutrophication-state-affecting environmental factors. This also implies the necessity of incorporating biological-mineral interactions in models, especially when system-wide studies are carried out.

\section{Data availability}

Observational and model data and related material are available for scientific use upon request to the corresponding author.

Data are in the process of being made publicly available via the COSYNA data management portal CODM: http:// codm.hzg.de/codm/ or, alternatively, doi:10.17616/R3K02T (Breitbach et al., 2016).

Author contributions. Richard Riethmüller planned and carried out the ScanFish measurements in the German Bight and took responsibility to ensure data quality. Eefke M. van der Lee conducted an intensive pre-analysis of the data. Ulf Gräwe provided hydrodynamical model results from GETM for the times of the cruises. Richard Hofmeister interpolated the 3-D GETM results to the ScanFish track. Joeran Maerz and Kai W. Wirtz discussed and outlined the general research approach. Joeran Maerz carried out the data analyses and prepared the manuscript. All coauthors contributed critically to the discussion and to the interpretation of the results and the compilation of the manuscript. 
Competing interests. The authors declare that they have no conflict of interest.

Acknowledgements. The authors thank the crew of the research vessel R/V Heincke, H. Rink, H. Thomas, M. Heineke and R. Kopetzky for operating the ScanFish and for the processing and quality assurance of the observational data and laboratory work, and we thank L. Merckelbach and G. Flöser for fruitful discussions. We would like to thank the two anonymous reviewers, who helped to improve our manuscript. This work was supported (i) by the German Federal Ministry of Research and Education in the framework of the projects PACE (The future of the Wadden Sea sediment fluxes: still keeping pace with sea level rise?, FKZ 030634A) and MOSSCO (Modular System for Shelves and Coasts, FKZ 03F0667A), (ii) by the Helmholtz society via the program PACES, and (iii) by the Niedersächsisches Ministerium für Wissenschaft und Kultur (MWK) and the Niedersächsisches Ministerium für Umwelt und Klimaschutz (MUK) in the framework of the WiMo project (Scientific monitoring concepts for the German Bight), and through the Coastal Observing System for Northern and Arctic Seas (COSYNA). The financing of further developments of the IOW's Baltic Monitoring Program and adaptations of numerical models (STB-MODAT) by the federal state government of Mecklenburg-Vorpommern is acknowledged by Ulf Gräwe. Supercomputing was provided by the North-German Supercomputing Alliance (HLRN).

The article processing charges for this open-access publication were covered by a Research

Centre of the Helmholtz Association.

Edited by: K. Juniper

Reviewed by: three anonymous referees

\section{References}

Ayukai, T. and Wolanski, E.: Importance of biologically mediated removal of fine sediments from Fly River plume Papua New Guinea, Estuar. Coast. Shelf. S., 44, 629-639, 1997.

Baschek, B., Schroeder, F., Brix, H., Riethmüller, R., Badewien, T. H., Breitbach, G., Brügge, B., Colijn, F., Doerffer, R., Eschenbach, C., Friedrich, J., Fischer, P., Garthe, S., Horstmann, J., Krasemann, H., Metfies, K., Ohle, N., Petersen, W., Pröfrock, D., Röttgers, R., Schlüter, M., Schulz, J., Schulz-Stellenfleth, J., Stanev, E., Winter, C., Wirtz, K., Wollschläger, J., Zielinski, O., and Ziemer, F.: The Coastal Observing System for Northern and Arctic Seas (COSYNA), Ocean Sci. Discuss., doi:10.5194/os2016-31, in review , 2016.

Becker, V., Schlauch, E., Behr, M., and Briesen, H.: Restructuring of colloidal aggregates in shear flow and limitations of the freedraining approximation, J. Colloid. Interface Sci., 339, 362-372, 2009.

Berhane, I., Sternberg, R. W., Kineke, G. C., Milligan, T. G., and Kranck, K.: The variability of suspended aggregates on the Amazon Continental Self, Cont. Shelf Res., 17, 267-285, 1997.
Black, K. S., Tolhurst, T. J., Paterson, D. M., and Hagerthy, S. E.: Working with natural cohesive sediments, J. Hydraul. Eng., 128, 2-8, 2002.

Breitbach, G., Krasemann, H., Behr, D., Beringer, S., Lange, U., Vo, N., and Schroeder, F.: Accessing diverse data comprehensively - CODM, the COSYNA data portal, Ocean Sci., 12, 909-923, doi:10.5194/os-12-909-2016, 2016 (data available at: http://codm.hzg.de/codm/).

Brockmann, U., Laane, R., and Postma, H.: Cycling of nutrient elements in the North Sea, Neth. J. Sea Res., 26, 239-264, 1990.

Burchard, H., Flöser, G., Staneva, J., Badewien, T., and Riethmüller, R.: Impact of density gradients on net sediment transport into the Wadden Sea, J. Phys. Oceanogr., 38, 566-587, 2008.

Burchard, H., Schuttelaars, H. M., and Geyer, W. R.: Residual sediment fluxes in weakly-to-periodically stratified estuaries and tidal inlets, J. Phys. Oceanogr., 43, 1841-1861, 2013.

Camp, T. R. and Stein, P. C.: Velocity gradients and internal work in fluid motion, J. Boston Soc. Civil Eng., 85, 219-237, 1943.

Canuto, V. M., Howard, A., Cheng, Y., and Dubovikov, M. S.: Ocean Turbulence. Part I: One-Point Closure Model-Momentum and Heat Vertical Diffusivities, J. Phys. Oceanogr., 31, 1413-1426, doi:10.1175/15200485(2001)031<1413:OTPIOP>2.0.CO;2, 2001.

Chang, T. S., Joerdel, O., Flemming, B., and Bartholomä, A.: The role of particle aggregation/disaggregation in muddy sediment dynamics and seasonal sediment turnover in a back-barrier tidal basin, East Frisian Wadden Sea, southern North Sea, Mar. Geol., 235, 49-61, 2006.

De La Rocha, C. L. and Passow, U.: Factors influencing the sinking of POC and the efficiency of the biological pump, Deep-Sea Res. PT II, 54, 639-658, 2007.

Decho, A. W.: Microbial exopolymer secretions in oceanic environments: Their role(s) in food web and marine processes, Oceanogr. Mar. Biol., 28, 73-153, 1990.

Dyer, K. R.: Sediment processes in estuaries: future research requirements, J. Geophys. Res., 94, 14327-14339, 1989.

Ebenhöh, W., Kohlmeier, C., Baretta, J. W., and Flöser, G.: Shallowness may be a major factor generating nutrient gradients in the Wadden Sea, Ecol. Model., 74, 241-252, 2004.

Eisma, D. and Kalf, J.: Distribution, organic content and particle size of suspended matter in the North Sea, Neth. J. Sea Res., 21, 265-285, 1987.

Fettweis, M.: Uncertainty of excess density and settling velocity of mud flocs derived from in situ measurements, Estuar. Coast. Shelf. S., 78, 426-436, 2008.

Fettweis, M. and Baeye, M.: Seasonal variation in concentration, size, and settling velocity of muddy marine flocs in the benthic boundary layer, J. Geophys. Res.-Oceans, 120, 5648-5667, doi:10.1002/2014JC010644, 2015.

Fettweis, M., Francken, F., Pison, V., and Van den Eynde, D.: Suspended particulate matter dynamics and aggregate sizes in a high turbidity area, Mar. Geol., 235, 63-74, 2006.

Fettweis, M., Monbaliu, J., Baeye, M., Nechad, B., and Van den Eynde, D.: Weather and climate induced spatial variability of surface suspended particulate matter concentration in the North Sea and the English Channel, Meth Oceanogr., 3-4, 25-39, 2012.

Fettweis, M., Baeye, M., Van der Zande, D., Van den Eynde, D., and Lee, B. J.: Seasonality of floc strength in the southern North Sea, J. Geophys. Res.-Oceans, 119, 1911-1926, 2014. 
Flöser, G., Burchard, H., and Riethmüller, R.: Observational evidence for estuarine circulation in the German Wadden Sea, Cont. Shelf Res., 31, 1633-1639, 2011.

Fofonoff, N. P. and Millard, R. C.: Algorithms for the computation of fundamental properties of seawater, UNESCO R M, 44, 1983.

Franks, P. J. S.: Has Sverdrups's critical depth hypothesis been tested? Mixed layers vs. turbulent layers, ICES J. Mar. Sci., doi:10.1093/icesjms/fsu175, 2014

Fugate, D. C. and Friedrichs, C. T.: Controls on suspended aggregate size in partially mixed estuaries, Estuar. Coast. Shelf. S., 58, 389-404, 2003.

Gibbs, R. J.: Estuarine flocs: their size, settling velocity and density, J. Geophys. Res., 90, 3249-3251, 1985.

Gräwe, U., Holtermann, P., Klingbeil, K., and Burchard, H.: Advantages of vertically adaptive coordinates in numerical models of stratified shelf seas, Ocean Model., 92, 56-68, doi:10.1016/j.ocemod.2015.05.008, 2015.

Grunwald, M., Dellwig, O., Kohlmeier, C., Kowalski, N., Beck, M., Badewien, T. H., Kotzur, S., Liebezeit, G., and Brumsack, H.J.: Nutrient dynamics in a back barrier tidal basin of the Southern North Sea: Time-series, model simulations, and budget estimates, J. Sea Res., 64, 199-212, 2010.

Hamm, C. E.: Interactive aggregation and sedimentation of diatoms and clay-sized lithogenic material, Limnol. Oceanogr., 47, 17901795, 2002.

Joint, I. and Pomroy, A.: Phytoplankton biomass and production in the southern North Sea, Mar. Ecol. Prog. Ser., 99, 169-182, 1993.

Kolmogorov, A. N.: The local structure of turbulence in incompressible viscous fluid for very large Reynolds numbers, Dokl Akad Nauk SSSR, 30, 301-305, in Russian; Translation e.g.: A. N. Kolmogorov, Proc. R. Soc. Lond. A (1991) 434, 9-13, 1941.

Kranenburg, C.: The fractal structure of cohesive sediment aggregates, Estuar. Coast. Shelf S., 39, 451-460, 1994.

Kranenburg, C.: Effects of floc strength on viscosity and deposition of cohesive sediment suspensions, Cont. Shelf Res., 19, 16651680, 1999.

Leipe, T., Loeffler, A., Emeis, K.-C., Jaehmlich, S., Bahlo, R., and Ziervogel, K.: Vertical patterns of suspended matter characteristics along a coastal-basin transect in the western Baltic sea, Estuar. Coast. Shelf S., 51, 789-804, 2000.

Li, H., Arias, M., Blauw, A., Los, H., Mynett, A. E., and Peters, S.: Enhancing generic ecological model for short-term prediction of Southern North Sea algal dynamics with remote sensing images, Ecol. Model., 221, 2435-2446, 2010.

Li, J. and Logan, B. E.: Size distributions and fractal properties of particles during a simulated phytoplankton bloom in a mesocosm, Deep-Sea Res. PT II, 42, 125-138, 1995.

Lindborg, E. and Brethouwer, G.: Vertical dispersion by stratified turbulence, J. Fluid Mech., 614, 303-314, 2008.

Logan, B. E. and Alldredge, A. L.: Potential for increased nutrient uptake by flocculating diatoms, Mar. Biol., 101, 443-450, 1989.

Maerz, J., Verney, R., Wirtz, K., and Feudel, U.: Modeling flocculation processes: intercomparison of a size class-based model and a distribution-based model, Cont. Shelf Res., 31, 84-93, doi:10.1016/j.csr.2010.05.011, 2011.

Maggi, F.: Biological flocculation of suspended particles in nutrient-rich aqueous ecosystems, J. Hydrol., 376, 116-125, 2009.
Manning, A. J. and Schoellhamer, D. H.: Factors controlling floc settling velocity along a longitudinal estuarine transect, Mar. Geol., 345, 266-280, 2013.

Mari, X., Torréton, J., Trinh, C., Bouvier, T., Thuoc, C., Lefebvre, J., and Ouillon, S.: Aggregation dynamics along a salinity gradient in the Bach Dang estuary, Estuar. Coast. Shelf S., 96, 151-158, 2012.

Meakin, P. and Jullien, R.: The effect of restructuring on the geometry of clusters formed by diffusion-limited, ballistic, and reaction-limited cluster-cluster aggregation, J. Chem. Phys., 89, 246-250, 1988.

Osborn, T. R. and Cox, C.: Oceanic fine structure, Geophys. Fluid Dyn., 3, 321-345, 1972.

Passow, U.: Switching perspectives: Do mineral fluxes determine particulate organic carbon fluxes or vice versa?, Geochem. Geophy. Geosy., 5, Q04002, doi:10.1029/2003GC000670, 2004.

Pejrup, M. and Mikkelsen, O. A.: Factors controlling the field settling velocity of cohesive sediment in estuaries, Estuar. Coast. Shelf S., 87, 177-185, 2010.

Pietrzak, J. D., de Boer, G. J., and Eleveld, M. A.: Mechanisms controlling the intra-annual mesoscale variability of SST and SPM in the southern North Sea, Cont. Shelf Res., 31, 594-610, 2011.

Pingree, R. D., Holligan, P. M., and Mardell, G. T.: The effects of vertical stability on phytoplankton distributions in the summer on the northwest European Shelf, Deep-Sea Res., 25, 1011-1028, 1978.

Postma, H.: Transport and accumulation of suspended matter in the Dutch Wadden Sea, Neth. J. Sea Res., 1, 148-190, 1961.

Postma, H.: Introduction to the symposium on organic matter in the Wadden Sea, Neth. Inst. S., 10, 15-22, 1984.

Puls, W., Kühl, H., Frohse, A., and König, P.: Measurements of the suspended matter settling velocity in the German Bight (North Sea), DeHyZ, 47, 259-276, 1995.

Röttgers, R., Krasemann, H., Schönfeld, W., and Heymann, K.: COSYNA Progress Report 2011, available at: http://www hzg.de/imperia/md/content/cosyna/progressreport2011_web.pdf (last access: August 2016), 2011.

Stal, L.: Microphytobenthos, their extracellular polymeric substances, and the morphogenesis of intertidal sediments, Geomicrobiol. J., 20, 463-478, 2003.

Staneva, J., Stanev, E. V., Wolf, J.-O., Badewien, T. H., Reuter, R., Flemming, B., Bartholomä, A., and Bolding, K.: Hydrodynamics and sediment dynamics in the German Bight. A focus on observations and numerical modelling in the East Frisian Wadden Sea, Cont. Shelf Res., 29, 302-319, 2009.

Stokes, G. G.: On the Effect of the Internal Friction of Fluids on the Motion of Pendulums, Cambridge Philos Trans, IX, 8-106, reprinted in Mathematical and Physical Papers, 2nd ed., Vol. 3. New York: Johnson Reprint Corp., p. 1, 1966, 1851.

Sündermann, J. and Pohlmann, T.: A brief analysis of North Sea physics, Oceanologia, 53, 663-689, 2011.

Tian, T., Merico, A., Su, J., Staneva, J., Wiltshire, K., and Wirtz, K.: Importance of resuspended sediment dynamics for the phytoplankton spring bloom in a coastal marine ecosystem, J. Sea Res., 62, 214-228, 2009.

Umlauf, L. and Burchard, H.: Second-order turbulence closure models for geophysical boundary layers. A review of recent work, Cont. Shelf Res., 25, 795-827, 2005. 
van Beusekom, J., Bot, P., Carstensen, J., Göbel, J., Lenhart, H., Pätsch, J., Petenati, T., Raabe, T., Reise, K., and Wetsteijn, B.: Eutrophication. Thematic Report No. 6, Quality Status Report 2009. Wadden Sea Ecosystem No. 25, edited by: Marencic, H. and de Vlas, J., Common Wadden Sea Secretariat, Trilateral Monitoring and Assessment Group, Wilhelmshaven, 3-21, available at: http://www.waddensea-secretariat.org/sites/default/files/ downloads/qsr-2009.pdf (last access: August 2016), 2009.

van Beusekom, J. E. E., Buschbaum, C., and Reise, K.: Wadden Sea tidal basins and the mediating role of the North Sea in ecological processes: scaling up of management?, Ocean Coast Manage., 68, 69-78, 2012.

van der Lee, E. M., Bowers, D., and Kyte, E.: Remote sensing of temporal and spatial patterns of suspended particle size in the Irish Sea in relation to the Kolmogorov microscale, Cont. Shelf Res., 29, 1213-1225, 2009. van Maren, D. S. and Winterwerp, J. C.: The role of flow asymmetry and mud properties on tidal flat sedimentation, Cont. Shelf Res., 60S, 71-84, 2013.

Van Straaten, L. M. J. U. and Kuenen, P. H.: Accumulation of fine grained sediments in the Dutch Wadden Sea, Geol. Mijnbouw, 19, 329-354, 1957.

Winterwerp, J. C.: A simple model for turbulence induced flocculation of cohesive sediment, J. Hydraulic Res., 36, 309-326, 1998. 